\title{
Does treatment of hypertension explain the decline in mortality from stroke?
}

\author{
RUTH BONITA， ROBERT BEAGLEHOLE
}

\begin{abstract}
Mortality from stroke has been declining in New Zealand since 1950 and at an accelerating rate since the early 1970s. Hypertension is the single most important risk factor for stroke. The temporal association between the recent decline in mortality and an increase in the proportion of patients with hypertension detected and treated led to the assumption of a cause and effect relation.

Data from studies of the prevalence of blood pressure carried out in the community and from therapeutic trials of the treatment of hypertension were used to estimate the proportion of the decline in mortality from stroke that could be accounted for by increased treatment of hypertension during 1973-82 in New Zealand. Treatment of hypertension was estimated to account for roughly $10 \%$ of the observed reduction in deaths from stroke. Greater understanding of the reasons for the decline in mortality from stroke is required.
\end{abstract}

\section{Introduction}

Mortality from stroke has been declining steadily in New Zealand and elsewhere for several decades,,$^{1.4}$ and the decline accelerated in the early 1970s, particularly among women. ${ }^{15}$ This decline could have been caused by a decrease in the incidence of stroke or improved rates of survival, or both. The most plausible explanation is that the incidence has fallen, although the evidence is as yet incomplete. ${ }^{6}$

Hypertension is the most important risk factor for stroke. Improved management of hypertension has been proposed as the main reason for the recent decline in mortality from stroke. ${ }^{48}$ Antihypertensive drugs have been available since the early 1950s, although the range of agents and their acceptability have increased considerably over the past 15 years. In several countries, including New Zealand, the detection, treatment, and control of hypertension have improved considerably over the past two decades. ${ }^{89}$

The greater decrease in mortality recently observed in women is consistent with the fact that more women than men are currently receiving (and using) antihypertensive treatment. ${ }^{9}$ This relation has not, however, been quantitatively assessed. This paper estimates the contribution of improved treatment of hypertension to the decline in mortality from stroke in New Zealand.

\footnotetext{
Departments of Medicine and Community Health and General Practice, School of Medicine, University of Auckland, New Zealand RUTH BONITA, MPH, PHD, research officer ROBERT BEAGLEHOLE, MD, FRACP, associate professor of epidemiology

Correspondence to: Dr Bonita.
}

\section{Methods}

We estimated the decline in mortality from stroke (8th and 9 th revisions of the International Classification of Disease codes 430-438) during 1973-82 using national mortality data and data from the Auckland Stroke Study. ${ }^{10-12}$ The improvement in the treatment and control of hypertension in New Zealand was estimated from studies carried out in Napier in $1973^{13}$ and in Auckland in $1982 .{ }^{9}$ We evaluated the effect of treatment of mild hypertension on mortality from stroke from the results of the Australian National Blood Pressure Study and the Hypertension Detection and Follow up Program. ${ }^{14} 15$

Relation between observed and expected numbers of deaths from stroke in New Zealand in 1982

\begin{tabular}{cccc}
\hline $\begin{array}{c}\text { Age } \\
(\text { years) }\end{array}$ & $\begin{array}{c}\text { Observed } \\
\text { No of deaths }\end{array}$ & $\begin{array}{c}\text { Expected } \\
\text { No of deaths }\end{array}$ & $\begin{array}{c}\text { Observed-expected } \\
\text { (\% decline) }\end{array}$ \\
\hline $30-39$ & 22 & 35 & $-13(37)$ \\
$40-49$ & 44 & 81 & $-37(46)$ \\
$50-59$ & 141 & 256 & $-115(45)$ \\
$60-69$ & 412 & 654 & $-242(37)$ \\
$70-79$ & 905 & 1430 & $-525(37)$ \\
$\geqslant 80$ & 1271 & 1939 & $-668(34)$ \\
\hline Total & 2795 & 4395 & $-1600(36)$ \\
\hline
\end{tabular}

*Men and women combined.

\section{Results}

If the national mortality from stroke for 1973 had still applied in 1982 there would have been 1600 more deaths from stroke in New Zealand than were actually observed in 1982 in men and women aged 30 or more; 407 $(25 \%)$ of these extra deaths would have occurred in people aged under 70 (table).

In 1982 the prevalence of hypertension among people aged 35-64 in Auckland was $21 \%$ in men and $19 \%$ in women. Hypertension was defined as systolic blood pressure of $160 \mathrm{~mm} \mathrm{Hg}$ or more or diastolic blood pressure of $95 \mathrm{~mm} \mathrm{Hg}$ or more, or both. Those with blood pressures within the normal range who were receiving pharmacological treatment for hypertension were included. Overall, $9 \%$ of men and $12 \%$ of women were receiving pharmacological treatment for their hypertension. The prevalence of hypertension in New Zealand and the proportion of patients receiving pharmacological treatment in 1973 were assumed to be the same as was found in Napier in 1973 , when the prevalence of hypertension was $17 \cdot 3 \%$ in men and $21.5 \%$ in women; overall only $4 \cdot 2 \%$ of men and $7 \cdot 5 \%$ of women were receiving treatment. From these two sets of data we estimated that an additional 72345 patients with hypertension aged 30-69 were receiving treatment in New Zealand in 1982 compared with 1973.

The Australian National Blood Pressure Study investigated the effects of treating healthy volunteers aged 30-69 with diastolic blood pressures of 95$109 \mathrm{~mm} \mathrm{Hg}$ who were not receiving treatment for high blood pressure and did not have a history of cardiovascular disease. The results of the study indicated that over one year the number of deaths from stroke in the group receiving treatment declined by $0.394 / 1000$ compared with the group receiving placebo. Thus treatment of an extra 72345 patients with hypertension in New Zealand in 1982 would be expected to have reduced the number of deaths from stroke by about $30(7 \cdot 4 \%$ of the total decline in mortality from stroke observed in those aged 30-69 in New Zealand in 1982). 
When the analysis was adjusted to take into consideration the $18 \%$ of patients in this age range who had had recurrent strokes the number of deaths to be explained was reduced to $334 .{ }^{12}$ This increased the contribution of control of hypertension to the decline in mortality from stroke to $9 \%$, which perhaps provides a fairer comparison with figures for subjects in the Australian trial, none of whom had a history of stroke before entry.

The Hypertension Detection and Follow up Program compared patients with hypertension (diastolic blood pressure $\geqslant 90 \mathrm{~mm} \mathrm{Hg}$, including those already receiving treatment for hypertension) receiving stepped care with those treated in the community. Among white participants a reduction in deaths from stroke occurred only in the patients aged $60-69$, being 0.89 and $1.61 / 1000$ for men and women, respectively. Thus treatment of 14180 extra people aged 60-69 in 1982 compared with 1973 would be expected to have reduced the number of deaths from stroke by 23 . This represents $9 \cdot 5 \%$ of the observed decline in those aged $60-69$ (or $5 \cdot 7 \%$ of the total observed decline in those aged 30-69).

\section{Discussion}

The temporal association between the recent decline in mortality from stroke in New Zealand and the improvement in the detection and treatment of hypertension has been striking in New Zealand and many other countries. ${ }^{1-5}$ This study suggests that less than $10 \%$ of the observed decline in mortality from stroke between 1973 and 1982 in New Zealanders aged 30-69 resulted from an increase in the proportion of people receiving pharmacological treatment for hypertension, as judged from randomised controlled trials conducted overseas.

Several assumptions were made in reaching these conclusions. Firstly, we applied the results from trials of the treatment of mild hypertension. Treatment of hypertension may be more effective in those with more severe disease, though only $12 \%$ of all patients with hypertension aged 35-64 in Auckland had a diastolic blood pressure $\geqslant 105 \mathrm{~mm} \mathrm{Hg}{ }^{9}$ It was reassuring that both trials produced similar estimates of the contribution of changes in the proportion of people receiving pharmacological treatment for hypertension. If anything, it could be argued that these estimates were generous as the level of control achieved in clinical trials is unlikely to occur in the general population.

It was also necessary to extrapolate from studies in Napier and Auckland to the total population of New Zealand because of the lack of comparable national studies. The prevalence of hypertension in the city of Napier, however, was similar to that observed in a rural community in New Zealand in 1975, supporting our assumption. ${ }^{16}$ Furthermore, the sampling frame in the 1982 Auckland study included almost one quarter of the total population of New Zealand.

The present assessment of the impact of treatment was based on mortality data for two separate years, 1973 and 1982. Mortality in the decade before 1973 was, however, relatively stable, and the decline after 1973 was consistent for all age groups and both sexes. ${ }^{1}$ Although we concentrated on the decline in the past decade, mortality from stroke in New Zealand has been declining at least since the 1950s; the overall decline thus began before effective antihypertensive treatment was available. ' ${ }^{\prime}$ Furthermore, as the table indicates, three quarters of the reduction in mortality occurred in people aged over 70 , yet the medical profession was more cautious in treating elderly patients with hypertension during this period.

The influence of secular trends on other risk factors for stroke such as serum lipid concentrations, blood glucose concentrations, oral contraceptives, diet, and cigarette smoking has not been investigated systematically. As these risk factors do not have consistently strong associations with stroke, ${ }^{17}$ however, it is unlikely that changes in the extent to which the population has been affected by these factors would explain much of the decline-for example, it has been shown that serum lipid concentrations have no consistent association with stroke. ${ }^{17}$ It is thus doubtful that the apparent recent decline in cholesterol concentrations in New Zealand ${ }^{18}$ would have had a substantial effect on the incidence of stroke or mortality, particularly as the decline in cholesterol concentrations apparently began much later than the fall in mortality from stroke. Diabetes accelerates the atherosclerotic process, but there is a low relative risk of stroke in non-hypertensive diabetics. ${ }^{19}$ Furthermore, it is unlikely that there has been a decline in the prevalence of diabetes or any major improvement in its management.

Cigarette smoking, on the other hand, has been shown to be an important risk factor for stroke in the population of Auckland; a synergistic effect between smoking and the treatment of hypertension has also been observed (Bonita $\mathrm{R}$, et al; unpublished results). There has been an acceleration in the decline of tobacco consumption since the mid $1970 \mathrm{~s},{ }^{20}$ and trends in cigarette smoking may have contributed more to the decline in mortality from stroke than has previously been recognised.

Although the risk of stroke in patients with transient ischaemic attack is high, the occurrence of transient ischaemic attack in the population is low. Surgical procedures such as carotid endarterectomy have yet to be proved to be effective, ${ }^{21}$ and only a few such operations are performed in New Zealand.

Other risk factors (not defined here) may have contributed to the decline. 22 Presumably those factors responsible for the decline in mortality that occurred before the widespread use of antihypertensive drugs are still important. It is also possible that small changes in the mean blood pressure of the population may have had a more pronounced effect on mortality from stroke than the treatment of hypertension. Unfortunately, there has been no adequate assessment of trends in mean blood pressure in the population of New Zealand.

Trends in cardiovascular disease are often cited to justify public health priorities and medical practice. ${ }^{23}$ Factors other than antihypertensive treatment appear to have contributed most to the decline in mortality from stroke. Information on long term trends in the incidence of stroke and survival is required. Before more resources are directed towards promoting pharmacological treatment of hypertension greater effort should perhaps be made to increase understanding of the reasons for the decline in the mortality from stroke.

$\mathrm{R}$ Bonita was supported by a grant from the Medical Research Council of New Zealand.

\section{References}

1 Bonita R, Beaglehole R. Trends in cerebrovascular disease mortality in New Zealand. NZ Med $\mathcal{f}$ 1982;95:411-4

2 Haberman S, Capildeo R, Rose FC. Diverging trends in cerebrovascular disease and ischaemic heart disease mortality. Stroke 1982;13:582-9.

3 Dobson AJ, Gibberd RW, Wheeler DJ, Leeder SR. Age specific trends in mortality from ischaemic heart disease and cerebrovascular disease in Australia. Am F Epidemiol 1981;113: 404-12.

4 Levy RI, Moskowitz J. Cardiovascular research: decade of progress, a decade of promise. Science 1982;217:121-9.

5 Soltero I, Liu K, Cooper R, Stamler J, Garside D. Trends in mortality from cerebrovascular diseases in the United States, 1960 to 1975. Stroke 1978;9:549-55.

6 Whisnant JP. The decline of stroke. Stroke 1984;15:160-8.

6 Whisnant JP. The decline of stroke. Stroke 1984;15:160-8.
7 Kannel WB, Wolf PA, Verter J, McNamarra PN. Epidemiologic assessment of the role of blood Kannel WB, Wolf PA, Verter J, McNamarra PN. Epidemiologic asses
pressure in stroke: the Framingham study. JAMA 1970;214:301-10.

8 Soltero I, Cooper R. Improved hypertension control and decline in cardiovascular mortality. Compr Ther 1980;6:60-4.

9 Jackson RT, Beaglehole R, Stewart AW. Blood pressure levels and the treatment of hypertension in Auckland, 1982. NZ Med F 1983;96:751-4.

10 National Health Statistics Centre. New Zealand health statistics report: mortality and demographic data. Wellington, New Zealand: National Health Statistics Centre, Department of Health, 1973.

11 National Health Statistics Centre. New Zealand health statistics report: mortality and demographic data. Wellington, New Zealand: National Health Statistics Centre, Department of Health, 1982

12 Bonita R, Beaglehole R, North JDK. Event incidence and case fatality rates of cerebrovascular disease in Auckland, New Zealand. Am $\mathcal{F}$ Epidemiol 1984;120:236-43.

13 Christmas BW. Blood pressure levels of an urban adult New Zealand population, Napier 1973. NZ Med f 1977;86:369-74.

14 Management Committee. Australian therapeutic trial in mild hypertension. Lancet 1980;i:1261-3.

14 Management Committee. Australian therapeutic trial in mild hypertension. Lancet $1980 ; 1: 1261-3$, Hypertension Detection and Follow-up Program Cooperative Group. Five-year findings of the
hypertension detection and follow-up program: reduction in stroke incidence among persons with high blood pressure. FAMA 1982;247:633-8.

16 Simpson RO, Waal-Manning JH, Bolli P, Spears GFS. The Milton survey: 2. Blood pressure and heart rate. NZ Med $\mathcal{F} 1978 ; 88: 1-4$.

17 Subcommittee on Risk Factors and Stroke of the Stroke Council. Risk factors in stroke. Special report. Stroke 1984;15:1105-11.

18 Jackson RT. The Auckland risk factor study. Auckland, New Zealand: University of Auckland, 1984. (MMS Thesis.)

19 Kannel WB. Epidemiology of cerebrovascular disease. In: Russell RWR, ed. Cerebral arterial disease. Edinburgh: Churchill Livingstone, 1976.

20 Hay DR, Foster FH. Intercensal trends in cigarette smoking in New Zealand. 1: Age, sex and ethnic status. NZ Med f 1984;97:283-5.

21 Warlow C. Carotid endarterectomy: does it work? Stroke 1984;15:1068-76.

22 Wilhelmsen L, Svardsudd K, Korsan-Bengtsen K, Larsson B, Welin L, Tibblin G. Fibrinogen as a risk factor for stroke and myocardial infarction. N Engl f Med 1984;311:501-5.

$23 \mathrm{Wing} \mathrm{S}$. The role of medicine in the decline of hypertension related mortality. Int 7 Health Serv 1984;14:649-66.

(Accepted 7 October 1985) 